\title{
ĐÁNH GIÁ KẾT QUẢ ĐIỀU TRỊ VIÊM TỦY KHÔNG HỒI PHỤC MộT THÌ Có HỖ TRợ LASER DIODE
}

\section{TÓM TẮT}

Mục tiêu: Khảo sát đặc điểm lâm sàng, X-quang và đánh giá kết quả điều trị viêm tủy không hồi phục một thì có hỗ trợ Laser diode. Đối tượng và phương pháp nghiên cứu: Nghiên cứu mô tả tiến cứu, có can thiệp lâm sàng, trên 35 với 38 răng, tuổi từ 10 đến 70, được chẩn đoán và điều trị hoai tử tủy. Đánh giá kết quả sau trám bít ống tủy, sau điêu trị 1 ngày, 1 tuần và 3 tháng. Kết quả: Kết quả lâm sàng sau điều trị 1 ngày: không đau chiếm 60,5\%, không có trường hợp nào đau nặng trở lên; sau điêuu trị 1 tuần: Tốt: 94,7\%; sau điều trị 1 tháng: Tốt 97,4\%. Kết quả $X$ quang sau sửa soan và trám bít ống tủy: Tốt: 92,1\%; sau 3 tháng: Tốt: 94,7\%.Không có trường hợp kém về lâm sàng và $X$ quang. Kết luận: Sử dụng laser diode trong điều trị viêm tủy không hồi phục 1 thì nên được áp dụng vì đây là điều trị hố trợ đơn giản, ít xâm lấn và có hiệu quả. khoa

Tư khóa: viêm tủy không hồi phục, Laser nha

\section{SUMMARY}

\section{EVALUATION OF SINGLE-VISIT} TREATMENT OUTCOMES OF IRREVERSIBLE PULPITIS WITH DIODE LASER

Objectivea: Surveying clinical feature, $\mathrm{X}$-ray, and evaluating treatment outcomes of irreversible pulpitis single visit with diode laser. Subjects and Methods: The study's methods are prospective and interventional study. A total of 35 to 38 teeth, being diagnosed with pulp necrosis and treated, 10 to 70 years of age. Assessment treatment results of obturation follow-ups 1 day, 1 weak, 3 months. Results: Post-operative outcomes 1 day after treatment: No pain accounted for $60,5 \%$, nonreporting severe pain. After 1 weak, good result occupied $94,7 \%$ and after 3 months it is $97,4 \%$. X-ray after shaping and obturated root canal : Good: $92,1 \%$, after 3 months $94,7 \%$. Non-reporting fail treatment in clinical traits and X-ray. Conclusion: We demonstrate that utilizing the diode laser for irreversible pulpitis single visit treatment should be applied because of simple, less invasive, effective characteristic.

Keyword: Irreversible pulpitis, Dentistry laser

\section{I. ĐĂT VẤN ĐỀ}

Trong những năm gần đây, chuyên ngành nội nha đã có những bước tiến nhanh, vượt bậc

\footnotetext{
*Tt Răng Hàm Mặt, Bệnh viện Trung ương Huế Chịu trách nhiệm chính: Nguyễn Hồng Lợi Email: drloivietnam@yahoo.com.vn Ngày nhân bài: 22.10.2021 Ngày phản biện khoa học: 17.12.2021 Ngày duyệt bài: 27.12.2021
}

\section{Nguyễn Hồng Lọii*, Nguyễn Hồ Phương Mai*}

trong cả chẩn đoán và điều tri. Vào cuối thâp niên 90, trâm NiTi ra đời, là một bước đột phá, giúp sửa soạn ống tủy nhanh, an toàn và hiệu quả; kết hợp với thuốc sát khuẩn ống tủy, các kỹ thuật tạo hình và trám bít ống tủy, điều trị nội nha đã thu được tỷ lệ thành công đáng kể.

Cùng với đó, trong lãnh vực nha khoa nói chung và nội nha nói riêng, nhiều loại laser đã được ứng dụng trên mô mềm và mô cứng trong miệng. Laser và nhất là Laser diode đã chứng tỏ hiệu quả trong việc làm thay đổi cấu trúc, hình dạng vách ống tủy; làm sạch lớp mùn, diệt khuẩn, làm tăng khả năng dán kín của vật liệu trám bít ống tủy...[1],[2],[3]. Nhiều nghiên cứu trên thế giới cũng như ơ Việt Nam về tác dụng hố trợ của Laser diode đã được tiến hành nhưng các nghiên cứu đa số được thực hiện trong phòng thí nghiệm, in-vitro, vẫn còn rất thiếu những nghiên cứu lâm sàng trên người. Do vậy chúng tôi tiến hành đề tài này với hai mục tiêu: (1) Khảo sát đặc điểm lâm sàng, $X$-quang viêm tủy không hồi phục. (2) Đánh giá kết quả điều trị viêm tủy không hồi phục một thì có hỗ trợ Laser diode.

\section{II. ĐỐI TƯƠ'NG VÀ PHƯƠNG PHÁP NGHIÊN CỨU}

2.1. Đối tượng nghiên cứu. Nghiên cứu được thực hiện trên 35 bệnh nhân với 38 răng bao gồm nhóm răng trước và răng tiền cối, tuổi 10 đến 70 được chẩn đoán và điều trị hoại tử tủy tại Khoa Nha tổng quát - Trung tâm Răng Hàm Mặt-Bệnh viện Trung ương Huế từ tháng 5/2020 đển tháng 10/2020.

\subsection{Phương pháp nghiên cứu}

Thiết kế nghiên cứu: Nghiên cứu mô tả, tiến cứu có can thiệp lâm sàng.

Phương pháp chọn mẫu: chọn mẫu ngẫu nhiên, không sát xuất theo mẫu thuần tiên.

Phương tiện nghiên cứu: (1) Phiếu nghiên cứu. (2) Phương tiện, máy móc dụng cụ khám và điều trị, bao gồm: Ghế máy nha khoa; Máy chụp phim KTS; Bộ dụng cụ khám răng: gương, kẹp gắp, thám trầm; Tay khoan, mũi khoan mở tủy; Máy đo chiều dài ống tủy: Propex II-Densly; Máy nội nha X-Smart, bộ trâm máy Protaper (Densply); Trâm gai, bộ nong dũa tay K file, lentulo, bộ lèn ngang (Mani); Thước đo chiều dài ống tủy, bơm kim tiêm súc rửa ống tủy; Thuốc tê, syringe nha khoa; Glyde (EDTA) của hãng Dentsply; Nước cất; Gutta-percha Protaper của 
hãng Densply; Côn phụ; Vật liệu phục hồi thân răng: GIC, Composite; Máy GEMINI-810+980 Diode Laser (ULTRADENT- PRODUCTS, INC.); Thiết bi an toàn: quần áo, kính bảo hô lọc tia có bước sóng $800-980 \mathrm{~nm}$ cho bác sĩ, trợ thủ và bệnh nhân.

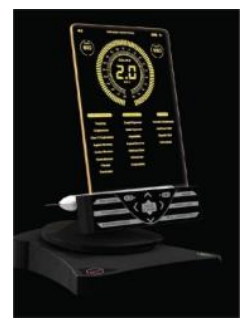

Hình 1: Máy GEMINI-810+910 Diode Laser (ULTRADENT PRODUCTS, INC)

Tóm tắt các bước tiến hành nghiên cứu và theo dõi:

Bước 1: Các đối tượng nghiên cứu được hỏi bệnh, khám lâm sàng, lập phiếu nghiên cứu.

Bước 2: Chụp phim cận chóp đánh giá sơ bộ số lượng chân răng và tình trạng ống tủy.

Bước 3: Sửa soạn ống tủy bằng trâm xoay Protaper máy.

Bước 4: Chiếu laser diode ống tủy dựa theo kỹ thuật được Gutknecht (2005) đề xuất sử dụng và hướng dẫn quy trình kỹ thuật bệnh viện (2013) của Bộ Y tễ [4]: Công suất 1,5W; Chế độ phát xung với mỗi xung $10 \mathrm{~ms}$ và nghỉ $10 \mathrm{~ms}$ giữa các xung; Lặp lại 4 lần, mỗi lần 5 giây, giữa mối lần chiếu nghỉ 5 giây; Động tác: kích hoạt nhiệt với giấy tối màu trước, đưa đầu tip đến chiều dài làm việc, rút ngắn lại $1 \mathrm{~mm}$, vừa chiếu tia, vừa thực hiện rút lên theo hình xoắn ốc, tốc độ $2 \mathrm{~mm} / \mathrm{giây}$.

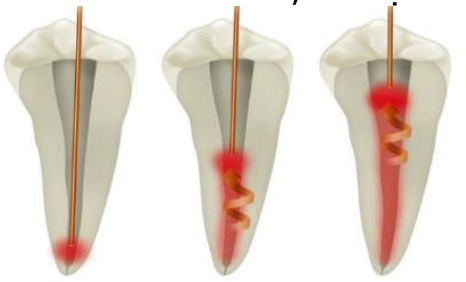

Hình 2: Động tác chiêu Laser được Gutknecht đề xuât (2005)

Bước 5: Trám bít ống tủy.

Bước 6: Trám kết thúc. Hẹn bệnh nhân tái khám sau điều trị 1 tuần, 3 tháng.

Các tiêu chí đánh giá. Đánh giá mức độ đau theo thang điểm VAS (visual analog scales): Công cụ này thường được sử dụng cho người trưởng thành để xác định mức độ đau hiện tại và mức độ của đau trong quá khứ. Mức độ đau từ 0 đến 10 , giải thích bằng lời cho $\mathrm{BN}$ hiểu cách tự đánh giá điểm đau cho bản thân trên thước hiển thị số. Ghi lại mức độ đau của BN để quyết định điều trị, theo dõi và so sánh giữa các lần khám.

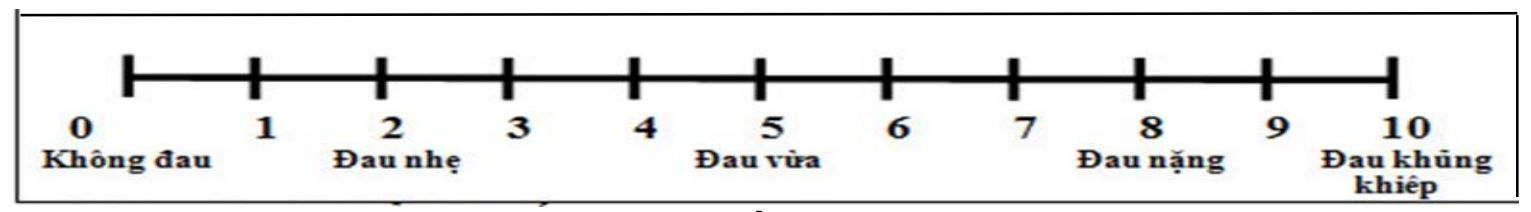

Hình 3: Thước hiển thị số VAS

Bảng 1: Tiêu chuẩn đánh giá $X$ quang khi đã trám bít ống tủy

\begin{tabular}{|c|c|c|c|}
\hline $\begin{array}{l}\text { Mức độ } \\
\text { Tình trạng }\end{array}$ & Tốt & Trung bình & Kém \\
\hline $\begin{array}{l}\text { Hình dạng } \\
\text { ống tủy }\end{array}$ & Thuôn đều hình côn & $\begin{array}{c}\text { Thuôn không đều hình } \\
\text { côn }\end{array}$ & $\begin{array}{l}\text { Sai đường, thủng } \\
\text { thành, gãy dụng cụ } \\
\text { trong ống tủy }\end{array}$ \\
\hline Số lượng ống tủy & Đầy đủ & Đầy đủ & Sót ống tủy \\
\hline $\begin{array}{l}\text { Chiều dài ống tủy } \\
\text { đã trám }\end{array}$ & $\begin{array}{l}\text { Trám đến đúng giới hạn chiều dài } \\
\text { làm việc trên Xquang (đúng chóp } \\
\text { hoặc cách chóp răng } 0,5-1 \text { mm tùy } \\
\text { trường hợp ống tủy). }\end{array}$ & $\begin{array}{l}\text { Trám thiếu hoặc quá } \\
\text { chóp răng<1mm. }\end{array}$ & $\begin{array}{l}\text { Trám thiếu hoặc quá } \\
\text { chóp >1mm. }\end{array}$ \\
\hline $\begin{array}{l}\text { Độ kín khít của } \\
\text { ống tủy đã trám }\end{array}$ & $\begin{array}{c}\text { Chất trám kín, độ cản quang đồng } \\
\text { nhất }\end{array}$ & $\begin{array}{l}\text { Có khoảng trống trong } \\
\text { khối chất trám }<1 \mathrm{~mm} \text {. }\end{array}$ & $\begin{array}{l}\text { Có khoảng trống trong } \\
\text { khối chất trám > 1mm }\end{array}$ \\
\hline
\end{tabular}

Bảng 2: Tiêu chuấn đánh giá kết quả lâm sàng sau điều trị (sau 1 tuần)

\begin{tabular}{|c|c|c|c|}
\hline \multicolumn{1}{|c|}{ Maúc độ } & Tốt & Trung bình & Kém \\
\hline Tình trạng & Không đau & $1-2$ ngày & Có \\
\hline Đau tự nhiên & Bình thường & Đau nhẹ & Không ăn nhai được \\
\hline Án nhai & Không đau & Đau nhẹ & Đau nhiêuu \\
\hline Gõ răng ngang, dọc & Không sưng & Không sưng & Đỏ nề, ấn đau \\
\hline Nướu quanh chóp rằng
\end{tabular}


VIETNAM MEDICAL JOURNAL N¹ - JANUARY - 2022

Bảng 3: Tiêu chuẩn đánh giá kêt quả lâm sàng sau điều trị (sau 3 tháng)

\begin{tabular}{|c|c|c|c|}
\hline Tình trạng Mức độ & Tốt & Trung bình & Kém \\
\hline Đauu tự nhiên & Không & Không & Đau từng đợt kèm theo sưng \\
\hline Ân nhai & Bình thường & Thỉnh thoảng đau nhẹ & Không nhai được \\
\hline Gõ răng ngang, dọc & Không đau & Không đau & Đau \\
\hline
\end{tabular}

Bảng 4: Tiêu chuấn đánh giá kết quả X quang sau điều trị

\begin{tabular}{|c|c|c|c|}
\hline Thời gian & Tốt & Trung bình & Kém \\
\hline Sau 3 tháng & $\begin{array}{l}\text { - Chất trám trong ống tủy kín. } \\
\text { - Khoảng dây chằng quanh răng } \\
\text { bình thường hoăc }<1 \mathrm{~mm} \text {. } \\
\text { - Không tổn thương quanh chóp }\end{array}$ & $\begin{array}{l}\text { - Chất trám co hở thành ở 1/3 } \\
\text { chóp. } \\
\text { - Dây chắng dãn rộng } \\
\text { - Không tổn thương quanh chóp }\end{array}$ & $\begin{array}{l}\text { Dây chằng dãn rộng } \\
\text { >2mm. } \\
\text { - Tổn thương } \\
\text { quanh chóp răng }\end{array}$ \\
\hline
\end{tabular}

\section{KẾT QUẢ NGHIÊN CứU}

3.1. Đặc điểm lâm sàng, cận lâm sàng

3.1.1. Đặc điểm chung. Trong số 35 bệnh nhân (nam 31,4\%, nữ 68,6\%), nhóm tuổi > 45 tuổi chiếm đa số $(51,4 \%)$.

Bảng 5. Phân bố theo triệu chứng cơ năng $(n=38)$

\begin{tabular}{|c|c|c|}
\hline Tính chất đau & Số răng & Tỷ lệ (\%) \\
\hline Không đau & 28 & 73,7 \\
\hline Đau do kích thích & 7 & 18,4 \\
\hline Đau tự nhiên & 3 & 7,9 \\
\hline Tống cộng & $\mathbf{3 8}$ & $\mathbf{1 0 0}$ \\
\hline
\end{tabular}

Bảng 6. Phân bố theo triệu chứng thực

thể ( $\boldsymbol{n}=\mathbf{3 8})$
\begin{tabular}{|c|c|c|}
$\begin{array}{c}\text { Án vùng } \\
\text { chóp, gõ dọc }\end{array}$ & Số răng & Tỷ lệ (\%) \\
\hline Không đau & 33 & 86,8 \\
\hline Đau ít & 5 & 13,2 \\
\hline Đau nhiều & 0 & 0 \\
\hline
\end{tabular}

Bảng 7. Hình ảnh tốn thương dây chăng trên X quang $(n=38)$

\begin{tabular}{|c|c|c|}
\hline $\begin{array}{c}\text { Tốn thương dây } \\
\text { chăng }\end{array}$ & Số răng & Tỷ lệ (\%) \\
\hline Không & 7 & 18,4 \\
\hline Có & 31 & 81,6 \\
\hline Tống cộng & $\mathbf{3 8}$ & $\mathbf{1 0 0}$ \\
\hline
\end{tabular}

Bảng 8. Phân bố số lượng ống từy $(n=38)$

\begin{tabular}{|c|c|c|c|c|c|c|c|c|c|c|c|c|}
\hline \multirow{2}{*}{\multicolumn{2}{|c|}{$\begin{array}{l}\text { Loại răng } \\
\text { Số ống tưy }\end{array}$}} & \multicolumn{5}{|c|}{ Hàm trên } & \multicolumn{5}{|c|}{$\begin{array}{l}\text { Hàm dưới } \\
\end{array}$} & \multirow{3}{*}{$\begin{array}{c}\text { Tổng } \\
30\end{array}$} \\
\hline & & R1 & $\mathbf{R 2}$ & $\mathbf{R 3}$ & R4 & R5 & R1 & $\mathbf{R 2}$ & $\mathbf{R 3}$ & R4 & R5 & \\
\hline \multirow{2}{*}{1} & $\mathrm{n}$ & 7 & 5 & 2 & 0 & 4 & 1 & 1 & 1 & 3 & 6 & \\
\hline & $\%$ & 18,4 & 13,2 & 5,3 & 0 & 10,5 & 2,6 & 2,6 & 2,6 & 7,9 & 15,8 & 78,9 \\
\hline \multirow{2}{*}{2} & $\mathrm{n}$ & 0 & 0 & 0 & 6 & 2 & 0 & 0 & 0 & 0 & 0 & 8 \\
\hline & $\%$ & 0 & 0 & 0 & 15,8 & 5,3 & 0 & 0 & 0 & 0 & 0 & 21,1 \\
\hline \multirow{2}{*}{3} & $\mathrm{n}$ & 0 & 0 & 0 & 0 & 0 & 0 & 0 & 0 & 0 & 0 & 0 \\
\hline & $\%$ & 0 & 0 & 0 & 0 & 0 & & 0 & 0 & 0 & 0 & 0 \\
\hline
\end{tabular}

3.2. Đánh giá kết quả điêu trị viêm tủy không hồi phục 1 thì có hố trợ Laser diode Bảng 9. Kểt quả lâm sàng sau điều trị 1 tuần $(n=38)$

\begin{tabular}{|c|c|c|}
\hline Kết quả & Số răng & Tỷ lệ (\%) \\
\hline Tốt & 36 & 94,7 \\
\hline Trung bình & 2 & 5,3 \\
\hline Kém & 0 & 0 \\
\hline Tống cộng & 38 & 100 \\
\hline
\end{tabular}

Bảng 10. Kết quả lâm sàng sau điều trị 3 tháng $(n=38)$

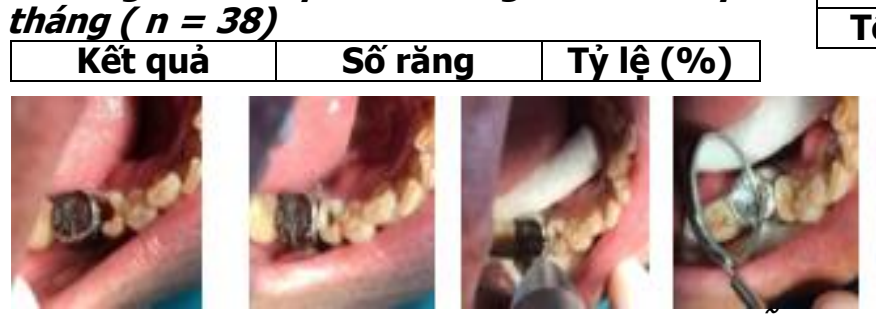

\begin{tabular}{|c|c|c|}
\hline Tốt & 37 & 97,4 \\
\hline Trung bình & 1 & 2,6 \\
\hline Kém & 0 & 0 \\
\hline Tống cộng & $\mathbf{3 8}$ & $\mathbf{1 0 0}$ \\
\hline
\end{tabular}

Bảng 11. Kêt quả $X$ quang sau điều trị 3 tháng $(n=38)$

\begin{tabular}{|c|c|c|}
\hline Kết quả & Số răng & Tỷ lệ (\%) \\
\hline Tốt & 36 & 94,7 \\
\hline Trung bình & 2 & 5,3 \\
\hline Kém & 0 & 0 \\
\hline Tống cộng & $\mathbf{3 8}$ & $\mathbf{1 0 0}$ \\
\hline
\end{tabular}

Hình 3. Quy trình điều trị tuỷ một thi có hỗ trợ lasediode và kết quả sau 1 tuần, 3 tháng 


\section{BÀN LUÂ̂N}

\section{1. Đăc điểm lâm sàng, $X$ quang}

Về giới: Tỷ lệ bệnh nhân nữ 68,6\% gấp 2 lần nam giới 31,4\%; tương tự kết quả nghiên cứu của Phạm Nữ Như Ý (nữ: 70\%, nam: 30\%) [5]. Theo y văn, ở mọi lứa tuổi, nữ giới đều có chỉ số SMT cao hơn nam giới dù rằng nữ giới giữ vệ sinh răng miệng sạch hơn và thường đi khám răng đều đặn hơn. Tuy nhiên, để xác định khách quan tỷ lệ này cần có nghiên cứu trên phạm vi lớn hơn.

Về nhóm tuổi: Trong nghiên cứu của chúng tôi, nhóm tuổi 46-70 chiếm tỷ lệ cao nhất $51,4 \%$; trong khi đó nghiên cứu của Pham Nữ Như Ý nhóm tuổi 10-25 chiếm tỷ lệ cao nhất $51 \%$ [5], của Võ Đăng Tuấn nhóm tuổi 26-45 chiếm tỷ lệ cao nhất 37,1\% [6]. Sự khác biệt này là do cách chon mẫu; ở Khoa Nha tổng quát chủ yếu là điều trị cho người lớn tuổi, có BHYT. Về dịch tễ học của bệnh sâu răng tăng dần theo tuổi, ngày nay tuổi thọ tăng do chất lượng cuộc sống cao và số răng mất theo tuổi già ngày càng ít đi nên răng sâu ở nhóm tuổi trên 46 ngày càng được phát hiện và điều trị nhiều hơn.

Về triệu chứng cơ năng với tính chất đau: Đa phần bệnh nhân không đau phù hợp với tủy đã chết toàn phần không còn đáp ứng với đau chiếm $73,7 \%$, đau chỉ có 10 bệnh nhân (10 răng) chiếm $26,3 \%$, khi mở và lấy tủy ở $1 / 3$ chóp tủy còn sống.

Về triệu chứng thực thể với ấn vùng chóp và gõ dọc: Ẩn vùng chóp và gõ dọc đa số các răng không đau chiếm đến $86,8 \%$, điều này có nghĩa là các răng đó chưa có biến chứng viêm quanh chóp.

Về tổn thương trên phim $X$ quang: Đối với răng hoại tử tủy, trên phim $X$ quang thường có hình ảnh dây chằng giãn rộng cùng với sự mất liên tục của laminadura. Trong nghiên cứu của chúng tôi chiếm $81,6 \%$, phù hợp với kết quả của tác giả Vũ Thị Bắc Hải 83,3\% [8], Võ Đăng Tuấn là $82,9 \%$ [6].

Về phân bố số lượng ống tủy: Trong nghiên cứu của chúng tôi, hầu hết các răng có 1 ống tủy, riêng răng cối nhỏ thứ 1 hàm trên có 2 ống tủy, răng cối nhỏ thứ 2 hàm trên $2 / 6$ trường hợp có 2 ống tủy; điều này cũng phù hợp với y văn. Tuy nhiên, theo Bùi Quý Dương $60 \%$ răng cửa dưới có 1 ống tủy, từ 16 đến $40 \%$ có 2 ống tủy [7]; do đó để điều trị tủy thành công mà không bỏ sót ống tủy cần nẳm vững giải phẫu răng, có $X$ quang hỗ trợ chẩn đoán kèm sửa soạn lối vào ống tủy thuận lợi nhất để phát hiện thêm các ống tủy khác.

4.2. Đánh giá kết quả điêu trị viêm tủy không hôi phục 1 thì có hỗ trợ laser diode.
Về kết quả $X$ quang sau sửa soạn và trám bít ống tủy: Đối tượng bệnh phần lớn là răng 1 chân, thẳng, loại trừ các răng bị cong, tắc, canxi hóa; được sửa soạn bằng trâm Protaper máy nên hình dạng ống tủy rộng, thuôn đều; cùng với sự hỗ trợ của laser diode, làm thay đổi hình thái và vách ống tủy, làm sạch lớp mùn, làm tăng khả năng dán kín của các vật liệu trám bít ống tủy. Chính vì thế, nghiên cứu của chúng tôi, kết quả $X$ quang sau trám bít ống tủy: tốt chiếm tỷ lệ rất cao $92,1 \%$, chỉ có 3 trường hợp trung bình do vật liệu trám quá chóp, mặc dù vậy chất trám trong ống tủy khít sát tốt, đều đặn, mật độ cản quang chất hàn cao. Kết quả nghiển cứu của Vũ Thị Bắc Hải cũng phù hợp với nghiên cứu của chúng tôi, tốt chiếm 90\% [8].

Đánh giá tình trạng đau sau điêu trị 1 ngày: Sau trám bít ống tủy 1 ngày, có $60,5 \%$ trường hợp không đau, 23,7\% đau nhẹ, 15,8\% đau vừa, không có trường hợp nào đau nặng và đau khủng khiếp. Nguyên nhân đau có thể là do sửa soạn, trám bít ống tủy, cũng có thể là do tác dụng nhiệt của laser diode, ngưỡng đau của từng người...; điều này đòi hỏi người nha sĩ phải chọn phương pháp sửa soạn ống tủy phù hợp, tránh bơm rửa thô bạo, chọn vật liệu và trám ống tủy thật chính xác đặc biệt là chọn phương pháp dùng laser khử khuẩn trong ống tủy, các thông số sử dụng trong điều trị.

Kết quả lâm sàng sau điều trị 1 tuần: Tốt: $94,7 \%$, trung bình 5,3\%. Kết quả của chúng tôi khá tương đồng với một số tác giả khác.

Trong 2 trường hợp đau nhẹ sau điêu trị 1 tuần là do chất trám quá chóp tạo phản ứng viêm gây đau. Trám bít ống tủy khít sát, đủ không gian 3 chiều là khâu rất quan trọng trong điều trị tủy. Trám ống tủy không hết chiêu dài để lại một khoảng trống sau trám ống tủy ở vùng chóp răng là nơi vi khuẩn tự do phát triển làm tổn thương chóp.Chuẩn bị ống tủy hơi thiếu còn ít nguy cơ hơn là quá chóp, đặc biệt những trường hợp ống tủy can xi hoá phẩn chóp đã bi hep. Khi có sư hiện diện của chất trám ngoài chóp răng sẽ có một phản ứng viêm, sự lành thương vùng chóp sẽ khó khăn, nhất là khi vật liệu không tiêu, một số trường hợp kích thích tắng sinh tế bào Malassez hình thành nang.

Đánh giá kết quả lâm sàng, Xquang sau điều trị 3 tháng: Về lâm sàng tốt: $97,4 \%$, trung bình: $2,6 \%$; về $X$ quang: Tốt: $94,7 \%$, trung bình: $5,3 \%$. Như thế sau 3 tháng theo dõi, kết quả đánh giá về lâm sàng tốt tăng thêm 1 răng, về mặt $X$ quang 2 răng còn ở mức độ kết quả trung bình do chất trám quá chóp, trong đó có 1 răng 
còn biểu hiện lâm sàng thỉnh thoảng đau nhẹ khi ăn nhai. Các trường hợp này cần được theo dõi, đánh giá sau 3 tháng nữa về lâm sàng và $X$ quang.

\section{KẾT LUÂN}

Kết quả nghiên cứu của chúng tôi có thể gợi ý rằng việc sử dụng laser diode hố trợ trong điều trị viêm tủy không hồi phục 1 thì là hiệu quả. Laser nói chung và Laser diode nói riêng đã chứng tỏ hiệu quả thay đổi cấu trúc hình thái và vách ống tủy, làm sạch lớp mùn, diệt khuẩn và cũng có khả năng làm tăng khả năng dán kín của các vât liêuu trám bít ống tủy. Trong những năm gần đây, ứng dụng laser diode trong điều trị nội nha đang tăng lên đặc biệt là vì khả năng diệt khuẩn của nó.

Đây là một liệu pháp điều trị hỗ trợ đơn giản, ít xâm lấn và có hiệu quả. Tuy vậy, đây là liệu pháp laser diệt khuẩn thông thường, còn dừng ở mức nghiên cứu, thử nghiệm, in vitro, rất thiếu những nghiên cứu trên lâm sàng nên cần được nghiên cứu thêm.

\section{TÀI LIẸU THAM KHẢO}

1. Ribeiro AC et al (2007), "Effect of diode laser $(810 \mathrm{~nm})$ irradiation on roof canal walls: thermographic and morphological studies", J Endod, 3, pp.252-255.

2. Stabholz A, Friedman S (1994), "Endodontic failures and Re-treatment", Cohen' Pathways of the pulp, Kenneth M. Hargreaves, Stephen Cohen, $6^{\text {th }}$ Edition, pp. 690-780.

3. Saydjari $\mathbf{Y}$ et al (2016), "Laser Application in Dentistry: Irradiation Effects of Nd:YAG $1064 \mathrm{~nm}$ and Laser Diode $810 \mathrm{~nm}$ and $980 \mathrm{~nm}$ in Infected Roof Canals-A Literature Overview", BioMed Reasearch International, pp.1-10.

4. Bộ Y Tế (2013), "Điều trị tủy răng có sử dụng laser và hàn kín hệ thống ống tủy bằng

5. Phạm Nữ Như Y̛ (2009), Nghiên cứu đặc điểm lâm sàng, $X$ quang và kết quả điều trị viêm quanh chó mạn bằng phương pháp nội nha, Luận án Chuyên khoa cấp II, Trường Đai hoc Y Dước Huế.

6. Võ Đăng Tuấn (2016), Đánh giá kết quả điều trị một thì tủy răng hoại tứ bằng hệ thống trâm quay Protaper máy, Luận án Chuyên khoa cấp II, Trường Đại học Y Dược Huế.

7. Bùi Quý Dướng (2007), "Giải phẫu răng", "Mở lối vào tủy", "Bớm rửa ông tủy", "Trám bít ống tủy", Nô̂i nha lâm sàng, Nhà xuất bản $Y$ hoc, Thành phố Hồ Chí Minh, tr. 29-38,39-40, 96-98, 119-122.

8. Vũ Thị Bắc Hải (2009), Nghiên cứu đặc điểm lâm sàng, cận lâm sàng, kết quả điều trị viêm tủy không có khả năng hồi phục bằng trâm tay Niti Protaper và trâm tay thông thường, Luân án Chuyên khoa cấp II, Trường Đại học Y Dược Huế.

\section{CÁC YẾU TỐ ẢNH HƯởNG ĐẾN TÍNH CHẤT VI CẦU XỐP ĐIỀU CHẾ BẰNG PHƯO'NG PHÁP BỐC HO'I DUNG MÔI: MộT NGHIÊN CỨU THEO THIẾT KẾ THỰC NGHIỆM}

\section{Lê Minh Quân ${ }^{1}$, Nguyễn Công Phi ${ }^{1}$, Lê Quan Nghiệm ${ }^{1}$}

\section{TÓM TẮT}

Mục tiêu: Đánh giá ảnh hưởng đồng thời của các yếu tổ công thức và quy trình trọng yếu đến kích thước, tỷ lệ tải dược chất và độ xổp của vi cầu điều chế bởi phương pháp bốc hơi dung môi từ nhũ tương. Đối tượng và phương pháp: Đối tượng nghiên cứu là vi câu tứ polyme ethyl cellulose chứa dược chất mô hình metronidazol được điều chế bằng phương pháp bốc hơi dung môi từ nhũ tương. Thiết kế thực nghiệm được thực hiên theo mô hình Box-Behnken. Kết quả: Tỷ lệ tải dược chất chịu tác động bởi nồng độ polyme và tốc đô đồng nhất hóa theo quy luât nghich đảo. Quy trình với các thông số điều chế tối ưu đã được thiết lập cu thể để tao được vi câuu ethyl cellulose chứa metronidazol có độ cầu $0,90 \pm 0,08$, tỷ lệ tải $14,44 \pm$

${ }^{1}$ Đại học Y Dước TPHCM

Chiu trách nhiệm chính: Lê Minh Quân

Email: leminhquan@ump.edu.vn

Ngày nhận bài: 21.10.2021

Ngày phản biên khoa họ: 17.12.2021

Ngày duyệt bài: 23.12.2021
$0,59(\%)$, kích thước $153,14 \pm 18,53 \mu m$, thể tích xốp $11,00 \pm 1,74 \mathrm{~mm}^{3} / \mathrm{g}$. Kết luận: Nghiên cứu đã xác định được mô hình ảnh hưởng của các thông số điều chế đến tính chất vi câu tạo thành, và thiết lập được quy trình tối ưu. Đây là cơ sở giúp kiểm soát được quy trình điều chế vi câu xốp, qua đó có thể thiết kế quy trình phù hợp để tạo được vi câu xốp có đặc tính định trước.

Tư khóa: vi cầu xốp, bốc hơi dung môi từ nhũ tương, thiết kễ thực nghiệm

\section{SUMMARY \\ EFFECT OF FORMULATION PARAMETERS ON POROUS MICROSPHERE PREPARED BY EMULSIFICATION - SOLVENT EVAPORATION METHOD: EXPERIMENTAL DESIGN}

Objective: Evaluate the potential simultaneous effect of critical formulation and process parameters on the particle mean size, encapsulation efficiency, sphericity, and porosity of the microspheres. Subjects and methods: Ethyl cellulose-based microspheres containing metronidazole were prepared by emulsification - solvent evaporation method. The 